\title{
ANTIBIOTIC SUSCEPTIBILITY, SEROTYPING AND PATHOGENICITY DETERMINATION OF AVIAN ESCHERICHIA COLI ISOLATED FROM COLIBACILLOSIS CASES IN BROILER CHICKEN IN ALJABEL ALAKHDAR REGION, LIBYA
}

\author{
ABDULKARIM F.H. ADAM ${ }^{1}$; NAJWA A. ISMAAEL ${ }^{2}$; \\ TUFAHAH M.O. ATIYAHULLAH ${ }^{2}$; ELHAM T. BENTAHER ${ }^{2}$; \\ OSAMA K. GAIDAN ${ }^{1}$ AND OMAR M. MERIZ ${ }^{2}$ \\ ${ }^{1}$ Department of Animal Medicine and Surgery Faculty of Veterinary Medicine. Omar Almukhtar \\ University, P.O.Box 919 elbeida, Libya. \\ ${ }^{2}$ Department of Preventive Medicine and Public Health Faculty of Veterinary Medicine. Omar \\ ALmukhtar University, P.O.Box 919 ELBeida, Libya.
}

Received: 5 September 2021; Accepted: 18 November 2021

\begin{abstract}
The main serotypes, pathogenicity, and antibiotic susceptibility of avian Escherichia coli isolated from colibacillosis cases in the Aljabel Al Akhdar region of Libya were investigated in this study. To determine the pathogenicity of E. coli isolates, Congo red binding, hemolysis, and lethality tests were conducted on Seventy-two unvaccinated broilers chicks on the day of hatching. Avian pathogen serotypes and antibacterial susceptibility testing to twelve antibiotics were also performed according to the standard methods. Results revealed that the only $\left(\mathrm{O}_{114}\right)$ serotype that had been orally inoculated caused mortality on the first day. While all $E$. coli isolates inoculated by subcutaneous route showed mortality on the first day. The highly pathogenic serotypes were $\left(\mathrm{O}_{26}\right)$ induced $(100 \%)$ mortality. Congo red (CR) binding assay showed that $(100 \%)$ of isolates were positive. Only $\left(\mathrm{O}_{26}\right)$ was found to be hemolytic. Seroty ping results revealed that $E$. coli strains belong to serotypes $\left(\mathrm{O}_{26}, \mathrm{O}_{111} \mathrm{O}_{114}\right.$, $\left.\mathrm{O}_{119}\right)$. According to the results, $(100 \%)$ of E. coli isolates were less sensitive to Cephalothin, Lincomycin, as well as Erythromycin, while the sensitivity level to Amoxyclav and Doxycycline was $(40 \%)$ and $(60 \%)$ respectively. Only $(20 \%)$ of E. coli isolates showed resistance to Enrofloxacin, Neomycin, Streptomycin, and Tetracycline. All strains were susceptible to Imipenem (100\%). Significantly, $\mathrm{O}_{26}$ serotype was highly resistant $(75 \%)$ to 9 out of 12 different antibiotics tested.
\end{abstract}

Keyword: Pathogenicity; Serotyping; Susceptibility; E.Coli

\section{INTRODUCTION}

It has been found the focus of several international type of research has

Corresponding author: Elham T. Bentaher E-mail address:eelham83@yahoo.com Present address: Department of Preventive Medicine and Public Health Faculty of Veterinary Medicine. Omar ALmukhtar University, P.O.Box 919 ELBeida, Libya. intensified their studies on Escherichia Coli due to its involvement in a wide outbreak of gastrointestinal illness in animals and humans (Deshmukh and Karpe, 2006). A link between $E$. coli and human illness has been discovered since chicken has been extensively embraced as a conveniently available source of meat. In Poultry, Colibacillosis is the most frequently reported infection during the year (Jones et al., 2000, Chowdhury and Das, 2003). It 
has been established as a common death causes in domestic birds (Kumar et al., 2005).

Colibacillosis is the most dominant bacterial disease in Chickens or Turkeys. It can cause a variety of symptoms of all ages, such as yolk sac omphalitis syndromes during the first week of life when the transmission of E. coli occurs by contaminated eggs or it is caused by inadequate induced hatchery sanitation. Colibacillosis commonly occurs as a secondary infection and can cause respiratory infections leading to pericarditis, perihepatitis and/or airsacculitis. E. coli can also cause synovitis and osteomyelitis as a result of systemic infection. Some types of E. coli are only pathogenic to Chicken [APEC, Avian pathogenic E.coli]. These strains are $\mathrm{O}_{1}, \mathrm{O}_{2}$, $\mathrm{O}_{35}$ and $\mathrm{O}_{78}$. Colicin and type 1 fimbrial seem to be correlated with virulence; however non-APEC strains can sometimes also cause Colibacillosis. Many E. coli strains which cause septicemia are associated with O Serogroups: O1, O2, O35, and O78, according to several surveys (Gross, 1958; Sojka and Carnaghan, 1961; Cheville and Arp, 1978; Cloud et al., 1985; Whittam and Wilson, 1988 and Dozois et al., 1992). However, other researchers found that avian Colibacillosis isolates have a large antigenic diversity (Allan et al., 1993 and White et al., 1990, 1993).

The extent to which a specific $\mathrm{O}$ serogroup is involved in illness is assumed to be dependent on geographically dependent. Although E. coli can be easily cultured, further serotyping is needed to identify whether E. coli isolates belong to APEC or not (Ulrich et al., 2008). Antimicrobial susceptibility testing of animal infections in vitro can assist veterinarians in selecting the most appropriate treatment (Jesus et al., 1997). Strains of resistant E. coli strains identified from cases suffering from colibacillosis are becoming more common, according to in vitro antibiotic sensitivity testing. Trimethoprim Sulphamethoxazole $(67 \%)$ and the new fluoroquinolones were resistant with a percentage of (13 to 24 $\%$ ) (Cloud et al., 1985; Goren, 1990; Allan et al., 1993; Amara et al., 1995; Peighambari et al., 1995 and Jesus et al., 1997). Either pathogenic or non-pathogenic organisms are valuable indicators when research is dependent on investigating the virulence characteristics of bacteria (B erkhoff and Vinal, 1986). The current research was carried out on the $E$. coli isolate from broiler farms in $\mathrm{Al} \mathrm{Jabal} \mathrm{Al}$ Akhdar region to identify serogrouping and pathogenicity, as well as to determine the efficacy kinds of antibiotics commonly used, the virulence of $E$. coli was also investigated.

\section{MATERIALS AND METHODS}

\section{Bacterial isolates:}

Five of $E$. coli strains, recovered from diseased broiler, were obtained from the preventive medicine and public health laboratory, faculty of veterinary medicine, Omar AL-Mukhtar University, Libya.

\section{Serotyping:}

The identification of $(\mathrm{O})$ somatic antigens was undertaken at the animal health research center, Egypt.

\section{Antimicrobial susceptibility test:}

According to the approach performed by (Bauer et al., 1966), all E. coli were evaluated by using the disk diffusion method on Muller Hinton agar (HiMedia). Antibiotics discs of Oxoid used in this work were Amoxyclav (AC) $(10 \mu \mathrm{g})$, Imipenem (IMP) $(10 \mu \mathrm{g})$, Streptomycin (S) Colistin sulphate (CT) $(25 \mu \mathrm{g})$, Cephalothin (KF) (30 $\mu \mathrm{g})$, Doxycycline (DO) $(30 \mu \mathrm{g})$, Tetracycline (TE) $(30 \mu \mathrm{g})$ Ery thromycin (E) $(15 \mu \mathrm{g})$, Enrofloxacin (ENR) (5 $\mu \mathrm{g})$, Gentamycin (GEN) $(10 \mu \mathrm{g})$, Lincomycin (Lin) $(15 \mu \mathrm{g})$, Neomycin $(\mathrm{N})(30 \mu \mathrm{g}), \quad(10$ $\mu \mathrm{g})$. 


\section{In vitro pathogenicity test:}

It was evaluated by:

\section{A-Hemolysis test:}

A plate of blood agar base containing 5\% sheep blood was streaked with an overnight culture of $E$. coli isolates. Then it was incubated at $37 \mathrm{C}^{\circ}$ for $24 \mathrm{hrs}$, and examined for a clear zone of hemolysis, indicating that it was hemolysis positive

\section{B-Congo Red dye- binding test:}

E. coli isolates were streaked on Tryptic soy agar containing an addition of $0.03 \%$ Congo red and $0.15 \%$ bile salt and incubated for 24 hours at $37^{\circ} \mathrm{C}$. Congo red positive was defined as the existence of red colonies, whilst white or grey colonies were classified as negative.

\section{In vivo pathogenicity test:}

A total of Seventy-two one-day-old unvaccinated broiler chicks (Breed: F Is hybrid) of different sex selected on the first day of life from an industrial hatchery (Kandula Company). Chicks were fed adlibitum during the experiment. Chicks were distributed into a completely randomized design to five groups with six birds each. The $5^{\text {th }}$ group was left as a control. Five $E$. coli strains including $\mathrm{O}_{26}, \mathrm{O}_{111}, \mathrm{O}_{114}$, and $\mathrm{O}_{119}$ were used; therefore, four groups were inoculated either subcutaneously or orally with a single dose of $0.25 \mathrm{ml}$ of brain-he art broth per chick, containing an average of $3 \times 10^{6} \mathrm{CFU}$ of each isolate.

Birds were maintained for seven days postinoculation and daily monitored for mortality. Dead birds were examined for lesions of septicemia (fibrinous perihepatitis, pericarditis, airsacculitis and Synovitis). On the seven days of age, the survival birds (Sick and healthy) were sacrificed and subjected to post mortem examination. Reisolates of $E$. Coli from the liver and organs were done on MacConky, tergitol 7 agar, and congo red (CR) agar. $E$. coli strains that produced any or all of the above lesions were considered invasive (Capable of producing septicemic disease).

\section{RESULTS}

\section{Serological Identification:}

$E$. coli isolates were serologically identified to different $\mathrm{O}$ groups. The most commonly isolated subgroups were $\mathrm{O}_{26}, \mathrm{O}_{111}, \mathrm{O}_{114}$, and $\mathrm{O}_{119}$ as shown in Table (1).

Table 1: Presenting (O) serotypes identified from avian E. coli isolates.

\begin{tabular}{cc}
\hline Strain & Serotype \\
\hline $\mathrm{EC}_{6}$ & $\mathrm{O}_{111}$ \\
\hline $\mathrm{EC}_{11}$ & $\mathrm{O}_{26}$ \\
\hline $\mathrm{EC}_{12}$ & $\mathrm{O}_{119}$ \\
\hline $\mathrm{EC}_{13}$ & $\mathrm{O}_{114}$ \\
\hline $\mathrm{EC}_{10}$ & $\mathrm{O}_{26}$ \\
\hline
\end{tabular}

Antibiotic susceptibility of $E$. coli isolates:

The antimicrobial susceptibility of $E$. coli subtypes outlined different percentages of resistance and sensitivity to the used antibiotics as utilized in this investigation Table (2). (100\%) of E. coli isolates were recorded to be resistant to Cephalothin, Lincomycin, and Erythromycin, while relatively few isolates were resistant $(40 \%$,
$60 \%$ ) to Amoxyclav and Doxycycline, respectively. Only (20\%) of $E$. coli isolates exhibited resistance to Enrofloxacin, Neomycin, Streptomycin and Tetracycline. All E. coli isolates have a high level of sensitive $(100 \%)$ to Imipenem. Significantly, $\mathrm{O}_{26}$ serotype was highly resistant $(75 \%)$ to 9 out of 12 different antibiotics tested. 
Table 2: Antibiotics susceptibility profile of E. coli strains.

\begin{tabular}{|c|c|c|c|c|c|c|c|c|c|c|c|c|c|c|c|}
\hline \multirow[b]{2}{*}{ 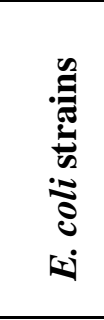 } & \multirow[b]{2}{*}{ 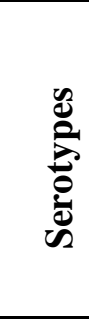 } & \multicolumn{12}{|c|}{ Antibiotics } & \multirow[b]{2}{*}{ 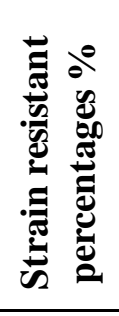 } & \multirow[b]{2}{*}{ 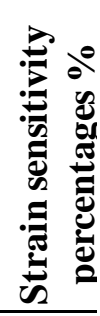 } \\
\hline & & IMP & DO & CT & KF & Lin & GEN & $\mathbf{E}$ & $\mathbf{A C}$ & ENR & $\mathbf{N}$ & $\mathbf{S}$ & TE & & \\
\hline EC6 & $\mathrm{O}_{111}$ & $S$ & $\mathrm{M}$ & $\mathrm{M}$ & $\mathrm{R}$ & $\mathrm{R}$ & M & $\mathrm{R}$ & $\mathrm{S}$ & $\mathrm{M}$ & $\mathrm{M}$ & $\mathrm{M}$ & $\mathrm{M}$ & $25 \%$ & 16 \\
\hline EC10 & $\mathrm{O}_{26}$ & $S$ & $\mathrm{R}$ & $\mathrm{M}$ & $\mathrm{R}$ & $\mathrm{R}$ & $\mathrm{M}$ & $\mathrm{R}$ & $\mathrm{R}$ & $\mathrm{M}$ & $M$ & $\mathrm{M}$ & $\mathrm{M}$ & $41 \%$ & 8.3 \\
\hline EC11 & $\mathrm{O}_{26}$ & $S$ & $\mathrm{R}$ & $\mathrm{M}$ & $\mathrm{R}$ & $\mathrm{R}$ & $\mathrm{M}$ & $\mathrm{R}$ & $\mathrm{R}$ & $\mathrm{R}$ & $\mathrm{R}$ & $\mathrm{R}$ & $\mathrm{R}$ & $75 \%$ & 8.3 \\
\hline EC12 & $\mathrm{O}_{119}$ & $\mathrm{~S}$ & $\mathrm{M}$ & $\mathrm{M}$ & $\mathrm{R}$ & $\mathrm{R}$ & $\mathrm{M}$ & $\mathrm{R}$ & $\mathrm{S}$ & $\mathrm{S}$ & $\mathrm{S}$ & $\mathrm{S}$ & $\mathrm{S}$ & $25 \%$ & 50 \\
\hline EC13 & $\mathrm{O}_{114}$ & $S$ & $\mathrm{R}$ & $\mathrm{M}$ & $\mathrm{R}$ & $\mathrm{R}$ & $\mathrm{M}$ & $\mathrm{R}$ & $\mathrm{M}$ & $\mathrm{M}$ & $\mathrm{M}$ & $\mathrm{M}$ & $\mathrm{M}$ & $33 \%$ & 8.3 \\
\hline
\end{tabular}

IMP=Imipenem, $\quad \mathrm{DO}=$ Doxycycline,$\quad \mathrm{CT}=\mathrm{Colistin} \quad$ sulphate $\quad \mathrm{KF}=$ Cephalothin, Lin=Lincomycin, GEN=Gentamycin, E=Erythromycin, AC=Amoxyclav, ENR=Enrofloxacin, $\mathrm{N}=$ Neomycin, $\mathrm{S}=$ Streptomycin, TE=Tetracycline.

$\mathrm{S}=$ Sensitivity $=\mathrm{m} 2.5 \mathrm{~mm}$ anta bet $30 \mathrm{ne}$

$\mathrm{R}=$ Resistant $=\mathrm{m} 0.0 \mathrm{~mm}$ anta bet $30 \mathrm{ne}$

$\mathrm{M}=$ Moderate $=\mathrm{m} 1.2 \mathrm{~mm}$ anta bet $30 \mathrm{ne}$

Results showed that only two chicks died (33\%) during the first-day post inoculation by oral route in $\mathrm{O}_{114}$ serotype group Table (3). while all $E$. coli inoculated subcutaneously showed mortality on the first day Table (4). The mortality rate was $(100 \%)$ for $\mathrm{O}_{26}$ within 24-48 hours post- inoculation. The Control group all survived.

Table 3: Showing the mortality rate after 1 and 7 days post inoculation by oral and route of $E$. coli strain.

\begin{tabular}{cccc}
\hline E. coli strain & Serotype & $\begin{array}{c}\text { A mortality rate after 1day } \\
\text { post inoculation by oral route }\end{array}$ & $\begin{array}{c}\text { Mortality rate after 7 days } \\
\text { post inoculation by oral route }\end{array}$ \\
\hline $\mathrm{EC} 6$ & $\mathrm{O}_{111}$ & 0 & 0 \\
\hline $\mathrm{EC} 11$ & $\mathrm{O}_{26}$ & 0 & 0 \\
\hline $\mathrm{EC} 12$ & $\mathrm{O}_{119}$ & 0 & 0 \\
\hline $\mathrm{EC} 13$ & $\mathrm{O}_{114}$ & $2(33 \%)$ & - \\
\hline $\mathrm{EC} 10$ & $\mathrm{O}_{26}$ & 0 & 0 \\
\hline Cont-ve & - & 0 & 0 \\
\hline
\end{tabular}

These data collected during a separate experiment

Con-ve $=$ control negative group.

-no death 
Table 4: Showing the mortality rate after1 and 7 days post inoculation by and subcutaneou s route of $E$. coli strain.

\begin{tabular}{cccc}
\hline E. coli strain & Serotype & $\begin{array}{c}\text { Mortality rate after 1 days } \\
\text { post inoculation by } \\
\text { subcutaneous route }\end{array}$ & $\begin{array}{c}\text { Mortality rate after 7 days } \\
\text { post inoculation by } \\
\text { subcutaneous route }\end{array}$ \\
\hline EC6 & $\mathbf{O}_{111}$ & $\mathbf{2 ( 3 3 \% )}$ & $\mathbf{4}(\mathbf{1 0 0 \% )}$ \\
\hline EC11 & $\mathbf{O}_{26}$ & $\mathbf{6}(\mathbf{1 0 0 \% )}$ & - \\
\hline EC12 & $\mathbf{O}_{119}$ & $\mathbf{2 ( 3 3 \% )}$ & $\mathbf{4 ( 6 0 \% )}$ \\
\hline EC13 & $\mathbf{O}_{114}$ & $\mathbf{2 ( 3 3 \% )}$ & $\mathbf{4 ( 6 0 \% )}$ \\
\hline EC10 & $\mathbf{O}_{26}$ & $\mathbf{6 ( 1 0 0 \% )}$ & - \\
\hline Cont-ve & - & $\mathbf{0}$ & $\mathbf{0}$ \\
\hline
\end{tabular}

These data collected during a separate experiment

Con-ve $=$ control negative group .

-no death because all group members died after 1 day post inoculation

Post mortem lesions in most carcasses showed severe to a mild degree of omphalitis (watery and congested yolk sac), hydro pericardium, visceral congestion, enlargement and congestion of liver, pericarditis, and precipitated urea in the ureter, congested lung, and mild airsaculitis. These lesions were displayed in chicks that died during the first two days post inoculation. No signs and lesions were reported in the control group.

\section{Hemolysis test:}

Results showed that only one isolate $\left(\mathrm{O}_{26}\right)$ produced hemoly sis on sheep blood agar.

\section{Congo red test:}

Result showed that all E. coli isolates $(100 \%)$ were positive to (CR).

\section{DISCUSSION}

Serological identification of E. coli isolates that used in this work were belonged to the $\mathrm{O}_{26}$. $\mathrm{O}_{111}, \mathrm{O}_{114}$, and $\mathrm{O}_{119}$ Table (1). All of these Serogroups are belong to the Enteropathogenic E. coli (EPEC), a phrase defined by (Neter, 1959) to characterize the serogroups of E.Coli, epidemiologically relevant to the epidemic of diarrhea in infants in the 1940s and the 1950s in the UK. As previously noted by (Ashraf et al., 2015), $\mathrm{O}_{111}$ serotype was recovered from a newly hatched chicken. (El-Jakee et al.,
2012) obtained $\mathrm{O}_{26}$ and $\mathrm{O}_{111}$ from chicken cloacal swabs. Another study by (Schroeder et al., 2002) identified $\mathrm{O}_{26}$ and $\mathrm{O}_{111}$ from humans, cows, turkey, and chicken.

The evaluation of the pathogenic bacterial susceptibility profile is a significant therapy guide to decrease the economic loss of $E$. coli infection (Costa et al., 2010). In this study, a resistance towards antimicrobial in the class of Cephalosporins, and Penicillin s were observed. These findings were in accordance with the previous study considering the usage of these antimicrobial as a crucial contributor in the development of antimicrobial resistance $E$. coli (Schroeder et al., 2002). All of these isolates showed resistance for Cephalothin, Lincomycin, and Ertyhromycin Table (2). Nevertheless, they were highly sensitive to Imipenem. This was in agreement with (Khan et al., 2014). This can be due to the uncommon use of Imipenem in the poultry industry in this country. In the current study, a moderate sensitivity to Enrorofloxacin was reported, this was in contrast to the study by (Robert et al., 2002), who showed resistance to Enrofloxacin (28\%). (Jesus et al., 1997) observed a high level of resistance $(94 \%)$ to Tetracycline, whereas $(20 \%)$ of resistance level was obtained in this study. 
Indiscriminate use of antibiotics and the rise of Carbapenem-resistant bacteria, according to a recent world and health organization report, are an alarming worldwide health hazard (WHO, 2014). As a result, the emergence and spread of carbapenemresistant $E$. coli strains can pose a threat to global public health. (Wen et al., 2018). E. coli is one of the most important etiological agents both for nosocomial and community -acquired infection in humans and the possibility of the transmission of resistant bacteria from meat- producing animals has been reported (Petersen et al., 2002; Oteo et $a l ., 2005)$.

As mentioned in table (3), only one serotype $\left(\mathrm{O}_{114}\right)$ strain caused the death at first- day post- inoculation by oral route, whereas by subcutaneous inoculation all $E$. coli strains caused death ranging from $60 \%$ to $100 \%$ table (4). These findings were in contrast with a study by (Goren, 1978) showed that chicks were much more susceptible to intra tracheal than oral inoculation. Also, he mentioned that serotype $\mathrm{O}_{78}$ appears to be much more pathogenic than $\mathrm{O}_{26}$. In our study, $\mathrm{O}_{26}$ was more pathogenic than other studied serotypes. Furthermore, septicemia was the most frequent challenge that occurred in either died or authorized birds subcutaneously inoculated. Accordingly, two out of five serotypes $\left(\mathrm{O}_{26}, \mathrm{O}_{114}\right)$ were classified as highly virulent serotypes.

A direct correlation had been found between Congo red binding and virulence for some bacteria and their ability to cause septicemia (Ellakany et al., 2019). All tested isolates of different serogroups were Cong Red positive. (Berkhoff and Vinal, 1986) found that clinically isolated E. Coli, which were $(\mathrm{CR}+)$, caused septicemic infection in chickens.

Hemolytic activity on blood agar is a characteristic of certain strains of $E$. coli (Melese, 2015). It was mentioned that hemolysin is considered an important mark of Entero-toxigenic virulence E. coli. In the current study, one out of five different serotypes $\left(\mathrm{O}_{26}\right)$ expressed hemolysin on sheep blood agar. On the contrary, (Brenda et al., 1993) reported that $\mathrm{O}_{1}, \mathrm{O}_{2}$, and $\mathrm{O}_{78}$ were the predominant serogroups involved in Colibacillosis, except that all of these serogroups did not produce hemolysin on sheep blood agar.

\section{CONCLUSION}

Multiresistance E. coli strains have emerged as a serious worldwide problem. As a result, rising antibiotic resistance knowledge and encouraging sensible antibiotic usage is critical to fighting infectious illnesses that affect human and animal health. It is not enough to minimize antibiotic use in terms of quantity; rather, it is necessary to enhance antibiotic usage in terms of quality.

\section{REFERENCES}

Allan, B.J.; Van den Hurk, J.V. and Potter, A.A. (1993): Characterization of Escherichia Coli isolated from cases of avian colibacillosis. Can. J. Vet. Res. 57, 146-151.

Amara, A.; Ziani, Z. and Bouzoubaa, K. (1995): Antibioresistance of Escherichia Coli Strains isolated in morocco from chickens with Colibacillosis. Vet. Microbiol. 43(4): 325-330.

Ashraf A. Abd El Tawab; Ahmed M. Ammar; Soad A. Nasef and Reem $M$. Reda (2015): Antibacterial resistance and resistance gene detriments of $E$. coli isolated from chicken. Benha veterinary medical journal, 28(2): 231-240.

Bauer, A.W.; Kirby, W.M.M.; Sherris, J.C. and Truck, M. (1966): Antibiotic susceptibility testing by standardized single disk method. Amer. J. Clin. Pathol., 45: 493-496.

Berkhoff, H.A. and Viral, S.C. (1986): Congo red medium to distinguish between invasine and Non- Invasive 
Escherichia Coli pathogenic for poultry. Avian Dis., 30(1):117-121.

Brenda, Y.; Allan, J.V.; Hurk, V.D. and Adrew, A.P. (1993): Characterization of Escherichia Coli isolation for cases of Avian Colibacillosis. Can. J. Vet. Res. (57): 146-151.

Chowdhury, M. and Das, R. (2003): Incidence of drug resistance in $E$. coli strains in West Bengal. Ind. Vet. J. 80:81-82.

Cheville, N.F. and Arp, L.H. (1978): Comparative pathogenic finding of Escherichia Coli infection in birds. JAVMA 173(5 pt 2): 584-587.

Cloud, S.S.; Rosenberger, J.K.; Fries, P.A.; Wilson, R.A. and odor, E.M. (1985): In vitro and vivo characterization of avian Escherichia Coli, I, serotypes, metabolic activity, and antibiotic sensitivity. Avian Dis. 29(4), $1084-$ 1093.

Costa, M.M.; Drescher, G.M.; Aboni, F.; Weber, S.S.; Schrank, A.; Vainstein, M.H.; Schrank, I.S. and Vargas, A.C. (2010): Virulence factors, antimicrobial resistance, and plasmid content of Escherichia Coli isolated in Swine commercial farms. Arq. Bras. Med. Vet. Zootec.62 (1): 30-36.

Deshmukh, A.S. and Karpe, A.G. (2006): In vitro transfer of plasmid in $E$. coli .Ind. J. Comp. Microbial. Immunol. Infect. Dis. (27): 32-34.

Dozois, C.M.; Fairbrother, J.M.; Hasel, J. and Bossj, M. (1992): Pap- and pilrelated DNA sequences and other virulence determinants associated with Escherichia Coli isolated from septicemic chickens and turkeys. Infect. Immun. 60, 2648-2656.

El-Jakee, J.K.; Mahmoud, R.M.; Samy, A.A.; El-Shabrawy, M.A.; Effat, M.M. and Gad El-Said, W.A. (2012): Molecular characterization of E. coli isolated from chicken, cattle and buffaloes. Int. J. Microbiol. Res., 3(1): 64-74.

Ellakany, Hany F.; Hatem S. Abd. Elhamid; Ibrahim, MS.; Nagwa S, Mostafa and Ammed B, Gado (2019): Isolation,
Serotyping, Pathogenicity and Antibiotic Sensitivity testing of Escherichia Coli from Broiler chickens in Egypt. JVS. 61(2):45-51.

Goren, E. (1990): Colibacillose bij pluimvee: etiologie, pathologie en therapie. pluimvee symposium. Upjohn-Nederland, Doorn, the Netherlands.

Goren. E. (1978): Observations on experimental infection of chicks with Escherichia Coli. Avian Pathol., 7: 213-224.

Gross, W.B. (1958): Symposium on chronic respiratory disease of poultry. II. The role of Escherichia Coli in the cause of chronic respiratory disease. Am. J. Vet. Res. 19, 448-452.

Jesus, E.B.; Miguel, B.; Azucena, M. and Jorge, B. (1997): Prevalence of bacterial resistance to quinolones and other Antimicrobials among Avian Escherichia Coli strains isolated from septicemia and health chickens in Spain. J. Clini. Micr. 2184-2185.

Jones, M.G.; Bokshi, K.N. and Mahanta, B. (2000): Isolation and identification, serotyping and antibiogram of $E$. coli mahaboobnagar district. Ind. Vet. J. 77: 4-6.

Khan, MS.; Akhtar, N.; Haque, ME.; Barua, A.; Chowdhury, T.; Mullick, R. and Mahmud, AM. (2014): Isolation and identification of nonplasmid multidrug resistant E. coli from poultry wastes in Chittagong, Bangladesh. J. Bacteriol parasitol 5: 182.

Kumar, N.; Kashyap, S.K.; Maharchandani, S. and Sharma, M.M. (2005): Characterization of $E$. coli strains associated with septicaemia in sheep. Ind. Vet. J. 82:6-8.

Melese, K. (2015): Isolation and characterization of bacteria associated with yolk sac infection (omphalitis) in chicks in Bishoftu poultry forms. Ethiopia. Msc Thesis. Addis Ababa University, college of veterinary medicine and Agriculture, Department of veterinary 
microbiology, immunology and veterinary Public health.

Neter, E. (1959): Enteritis due to enteropathogenic Escherichia Coli present day status and unsolved problems. J. pediator. 55: 223-239.

Oteo, J.; Lizaro, E.; De Abajo, FJ.; Campos, I. and Spanish members of Earss (2005): Antimicrobial resistant invasive Escherichia Coli Spain. Emerg. Infect. Dis. 11: 546553.

Peighambari, S.M.; Vaillaneourt, J.P.; Wilson, R.A. and Gyles, C.L. (1995): Characteristics of Escherichia Coli isolates from avian cellulitis. Avian Dis. 39, 116- 124.

Petersen, A.; Andersen, J.S.; Kaewmak, T.; Somsiri, T. and Dalsgaarat, A. (2002): Impact of integrated fish farming on antimicrobial resistance in a pond environment. Appl. Environ. Microbial. 68. PP. 6036-6042.

Robert, H.; John, B.K.; Pawin, P.; Keiko, $H$. and Christina, Z. (2002): Prevalence of salmonella and E. coli and their resistance to antimicrobial agents, in farming communities in north Thailand. Medicine center, Michigan. St. Univ. East Lansing USA. (33): 120-126.

Schroeder, C.M.; Zhao, C.W. and Debroy, C. (2002): Antimicrobial resistance of Escherichia Coli O157 isolated from humans, Cattle, Swine, and food. Appl. Environ. Microbial. 68:576581.
Sojka, W.J. and Carnaghan, R.B.A. (1961): Escherichia Coli infection in poultry. Res. Vet. Sci. 2, 340-353.

Ulrich, L.; Antonia, R. and Timothy, S.C. (2008): Guideline for antimicrobial use in poultry, chapter8. Cityed by Guide Antimicrobial use in Animals. Edited by luca Guardabass, lars B. Jensen and Hilde Kruse.

Wen, YL.; Hui, YL.; Guang, CD.; Yong, Xz.; Shuai, YC.; Hai, YY. and yuan, $L X$. (2018): Emeregance and mechanism of carbapenem- resistant Escherichia Coli in Henan, China. Jour. Infect. Public. Health. 11: 347 351.

Whittam, T.S. and Wilson, S.A. (1988): Genetic relationships among pathogenic strains of avian Escherichia Coli. Infect. Immun. 56, 2458-2466.

White, D.G.; Wilson, R.A.; San Gabiiel, A.; Saco, M. and Whittam, T.S. (1990): Genetic relationships among of avian Escherichia Coli associated with swollen- head syndrome. Infect. Immin. 58, 3613-3620.

White, D.G.; Wilson, R.A.; Emery, D.A.; Nagaraja, K.V. and Whittam, T.S. (1993): Clonal diversity among strains of Escherichia Coli incriminated in turkey Colisepticemia. Vet. Microbiol. 34, 19-34.

WHO (2014): Antimicrobial resistance global report on surveillance: 2014 summary. 